\title{
Partial Replacement of Cement in Concrete by Metakaolin and Marble Dust
}

\author{
Shahid Ashraf Shah, Ashish Kumar
}

\begin{abstract}
Though various admixtures are available, confined examinations have been done in India on the use of china soil (Metakaolin) and marble dust for the headway of great bond. Metakaolin (MK) and marble buildup is a mineral admixture, whose potential isn't yet totally attempted. MK is a valuable cementitious material gotten from warmth treatment of trademark stores of kaolin. MK shows high pozzolana reactivity due to their indistinguishable structure and high surface district. On the other hand move of marble powder (MP) from the marble business is one of the natural issues today.

The use of marble powder can be used for improvement reason. The substitutions is done to some degree in various degrees and its effect on properties of concrete is thought about. Partial substitution of bond has been done at 3\%, 6\%, 9\%, 12\%, $15 \%$ with MK(Metakaolin) and 10\%(constant) with MP (Marble Powder). Compressive similarly as inflexibility of bond made with MK-MP has been differentiated and customary concrete of assessment M30. Solidness of bond was in like manner separated with Rapid chloride Migration Test (RCMT). Result exhibits that there is an increment of solidarity with the development of MK and MP. The upgraded quality estimation of concrete was practiced for both compressive similarly as split inflexibility at 9\%MK and $10 \% \mathrm{MP}$. The results close that, the usage of Metakaolin Concrete (MKC) has improved the introduction of bond under various conditions.
\end{abstract}

Keywords: Metakaolin, Marble Dust, M 30 concrete.

\section{INTRODUCTION}

Structural Engineering manages the plan, development and support of the physical and normally assembled condition, including works like streets, dams, parks and diversion, spans etc .For these development works, enormous Quantity of bond is utilized so concrete is one of most widely utilized development materials on the planet. Henceforth, it has been appropriately named as the spine to the foundation advancement of a country. To meet out this quick foundation advancement a colossal amount of cement is required. Cement is a composite material which has moderately high compressive quality, yet fundamentally lowers rigidity. At present, for an assortment of reasons, the solid development industry isn't economical. Right off the bat, it devours enormous amounts of virgin materials which can stay for next ages. Furthermore, the foremost folio in cement is Portland bond, the generation of which is a noteworthy supporter of ozone harming substance emanations that are embroiled in a worldwide temperature alteration and environmental change. Thirdly, many solid structures experience the ill effects of absence of toughness which may squander the characteristic

Revised Manuscript Received on February 10, 2020.

* Correspondence Author

Shahid Ashraf shah ,Civil Engineering Department, RIMT University, Punjab, India, shahidashrafshah1990@gmail.com

Ashish kumar,Civil Engineering Department ,RIMT

University,Punjab,india. 99ashishsharma99@gmail.com assets. A noteworthy part of cement will be bond and it is one of the three essential makers of carbon dioxide, a noteworthy ozone harming substance. Around $900 \mathrm{~kg}$ of $\mathrm{CO} 2$ are discharged for each ton of cement.

The principle wellsprings of METAKAOLIN are either kaolin or paper ooze, after reasonable warm treatment. The ideal temperature for warming kaolin so as to acquire METAKAOLIN with a high pozzolanic file is as yet not the same as one specialist to another. The warming time frame likewise is still precisely unsure. The ideal temperature for warming kaolin to acquire METAKAOLIN might extend from $600 \square \mathrm{C}$ to $850 \square \mathrm{C}$ for periods going from $1 \mathrm{~h}$ to $12 \mathrm{~h}$. Directly a lot of marble residue is produced in common stone preparing plants with a significant effect on condition and people.

Marble and rock stone preparing is one of the most flourishing industry the impacts if differing marble residue substance on the physical and mechanical properties of new and solidified cement have been examined. Slump and air substance of new concrete and assimilation and compressive quality of solidified concrete were likewise examined. Test outcomes demonstrate that this modern bi item is fit for improving solidified solid execution up to $9 \%$ and $10 \%$,Enhancing new solid conduct and can be utilized in building solid blends containing white bond. The compressive quality of cement was estimated for 7 and 28 days. So as to assess the impacts of marble dust on mechanical conduct, a wide range of mortar blends were tried.

\section{Main Sources of Metakaolin:}

Metakaolin is the anhydrous calcined type of the mud mineral kaolinite. Minerals that are wealthy in kaolinite are known as china mud or kaolin, generally utilized in the assembling of porcelain. The molecule size of metakaolin is littler than concrete particles, however not as fine as silica fume. Metakaolin can be created from an assortment of essential and optional sources containing kaolinite: Principle wellsprings of kaolinite as well as the key MK makers are situated in mud stores in Georgia, U.S. what's more, Cornwall, U.K. The cost of $\mathrm{MK}$ in Canada is about equivalent to SF and ranges among $\$ 400$ and $\$ 600$ per ton relying upon the area

- High purity kaolin deposits

- Kaolinite deposits or tropical soils of lower purity

- Paper sludge waste (if containing kaolinite)

- Oil sand tailings (if containing kaolinite)

\section{Sources of Metakaolin in the state of jammu and} Kashmir

There is a wide scope of Mineral Resources in J\&K State. The important minerals are Limestone, Gypsum, Dolomite, Quartzite besides building stones like, Slate, Marble, Granite etc. 
Lot of minerals are also found in the state of jammu and Kashmir, Among such minerals metakaolin is one found in the districts of Udhampur and Doda.

Kaolinite is an earth delivered by the decay in-situ of the felspar. It is the common (unwashed) china mud. Kaolinite is found in relationship with bauxite stores of Jammu. It happens between extraordinary limestone and breccia and nummulitics and coal proportions of bauxite arrangement of the Salal, Songarmar and Chakar territories. The neighborhood name of the mineral is Makol. It is utilized for white-washing purposes. Kaolinite stores are accessible upto a thickness of one to four meters in the regions of its event which can be utilized effec-tively in stoneware making.

\section{OBJCTIVES}

- To study the behavior of concrete for various mixes with the strength parameters and workability parameters

- To evaluate the protective capacity of concrete produced with MK and MP in relation to the transportation and penetration of chlorides

- To obtain an indicative of an internal structure of concrete.

- MK and MP are freely available and structure becomes economical.

\section{METHODOLOGY}

\section{PREPARATION AND CURING OF SPECIMEN}

- In this research work 73 Standard cubic specimens of size $150 \mathrm{~mm}$ (four sample for each percentage of Metakaolin and marble powder) were casted for the compressive strength of concrete and 73 standard cylindrical mould of size $100 \mathrm{~mm}$ diameter and $200 \mathrm{~mm}$ height (four sample for each percentage of Metakaolin and marble powder) were casted for split tensile strength of concrete, For RCMT, 30 Specimen of $10 \mathrm{~cm}$ diameter and $20 \mathrm{~cm}$ height(4 sample for each percentage of MK-MP) were casted and was kept under curing for 7, 14 days \& 28 days of age.

- Molds of measurement 150x150x150 mm are required for throwing of the 3D square example for compressive quality test. The 3D square shape plates are evacuated first and after that cleaned. Subsequent to cleaning, the form plates are gathered and the jolts are completely tight. The solid shape side countenances ought to be parallel and slender layer of oil ought to be connected on all appearances of the form. At that point the solid example ought to be taken and ought to be blended. Subsequent to blending the example, the 3D square ought to be filled at the earliest opportunity. The solid example ought to be filled in three layers around $5 \mathrm{~cm}$. while filling the molds the solid ought to be symmetrically conveyed inside the molds. Each layer ought to be packed by packing bar at least 35 strokes. The strokes will enter into the basic layer and the base layer. Where voids are left by the packing pole, the sides of the shape will be tapped to close the voids. Whenever required the molds will be vibrated on the vibrator.

At that point the shape ought to be put on safe spot till 24 hours. Following 24 hours the block ought to be expelled from the shape and after that put into the relieving tank.

\section{RESULT AND DISCUSSIONS}

\section{Strength Analysis: Compressive \& Tensile strength:}

Compressive and split rigidity of cement is tried at various level of MK and MP from $0 \%$ to $15 \% \mathrm{MK}$ and $0 \% \& 10 \%$ MP (consistent). For compressive quality of cement, 73 shapes was casted with four examples of every rate variety of MK and MP. The Compressive quality of cement has been tried at 7 days, 14 days and 28 days of restoring for Initial addition in quality of solid, middle increase of solidarity in concrete and last quality of cement individually. Pressure testing machine is utilized for testing the compressive quality of cement. At the season of testing the 3D square is taken out from water and dried and afterward tried keeping the smooth faces in upper position. Thus, For Split elasticity 73 chamber of $15 \mathrm{~cm}$ and $20 \mathrm{~cm}$ tallness was set up at various rate expansion of MK\&MP at 7,14 and 28 Days of restoring. The quality of cement is particularly reliant up on relieving for example the hydration response .The sort and measure of bond utilized in cement decides the hydration response. In this examination Ultra Tech OPC 43 evaluation of cement is utilized. The outcome investigation of compressive quality and split elasticity with halfway substitution of concrete by

MK and MP is appeared in Table 1 for all extraordinary level of MK-MP at 7,14 and 28 days of restoring

\section{COMPRESSIVE STRENGTH TEST:}

The Compressive Strength contrasted with control example with different rates of Metakaolin and marble dust. Compressive Strength after effects of examples displayed. The multi day Compressive Strength differed somewhere in the range of 45 and $55 \mathrm{~N} / \mathrm{mm} 2$. The multi day strength fluctuated somewhere in the range of 61 and $73 \mathrm{~N} / \mathrm{mm} 2$. The $20 \%$ replacement $\mathrm{MK}$ and marble dust blend displayed lower strengths similarly than the other MK rates. All the solid $\mathrm{s}$ including the control accomplished their objective strength of $60 \mathrm{~N} / \mathrm{mm} 2$ at 28 days and every one of the cements accomplished strength of more than 70MPa. Fig. 5.1 presents the connection between Compressive Strength and MK rates at 7 and 28 days. The most noteworthy for the MK15 blends accomplishing strength of $72.7 \mathrm{~N} / \mathrm{mm} 2$ at 28days. This unmistakably demonstrates the replacement level of $15 \%$ was the optimum Compressive Strength is concerned.

Following 28 days the compressive strength for MK and marble dust $3 \%$ increments in $4.36 \%$, when thought about to control example.

The compressive strength for $6 \%, 9 \%$ and $12 \%$ increments in $13.73 \%, 17.45 \%$ and $12.44 \%$ separately. MK $9 \%$ increments in higher strength, when contrasted with all different blends 
Table 1:- 7-Days compressive strength Analysis

\begin{tabular}{|c|c|}
\hline $\begin{array}{l}\text { Replacement } \\
\text { Percentage } \\
\text { MK-MP(\%) }\end{array}$ & $\begin{array}{l}\text { Compressive } \\
\text { Strength (N/mm }\end{array}$ \\
\hline $0 \%-0 \%$ & 24.9 \\
\hline $3 \%-10 \%$ & 25.75 \\
\hline $6 \%-10 \%$ & 27.95 \\
\hline $9 \%-10 \%$ & 34.19 \\
\hline $12 \%-10 \%$ & 33.8 \\
\hline $15 \%-10 \%$ & 30.12 \\
\hline
\end{tabular}

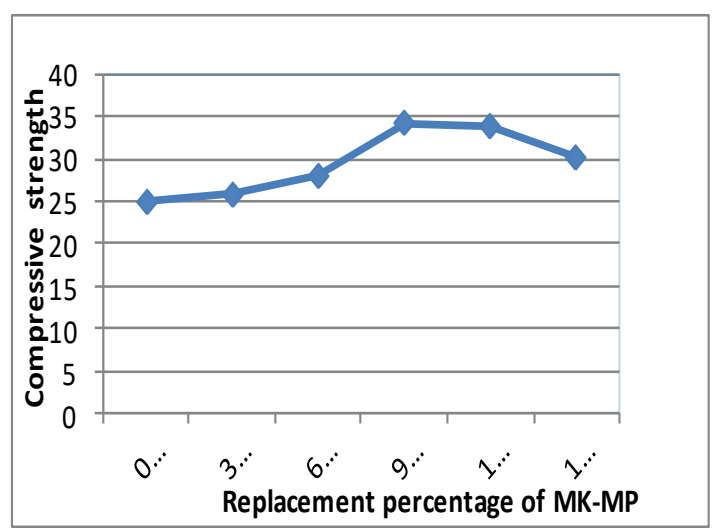

Graph no 1:-7-Days compressive strength Analysis

Table : 2 14-Days Analysis of Cube

\begin{tabular}{|c|c|}
\hline $\begin{array}{c}\text { Replacement percentage } \\
\text { of MK-MP }(\%)\end{array}$ & $\begin{array}{c}\text { Compressive Strength } \\
\left(\mathrm{N} / \mathrm{mm}^{2}\right)\end{array}$ \\
\hline $0 \%-0 \%$ & 34.12 \\
\hline $3 \%-10 \%$ & 34.45 \\
\hline $6 \%-10 \%$ & 34.86 \\
\hline $9 \%-10 \%$ & 35.47 \\
\hline $12 \%-10 \%$ & 35.12 \\
\hline $15 \%-10 \%$ & 34.57 \\
\hline
\end{tabular}

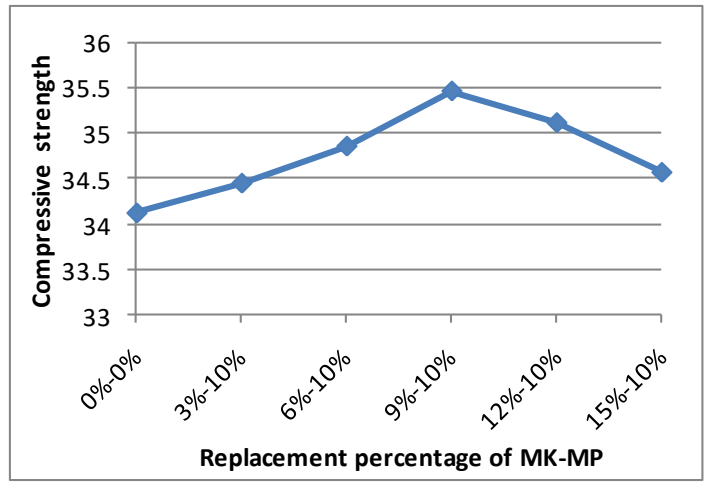

Graph 2:- 14-Days Analysis of Cube

From above results it is cleared that maximum compressive strength is obtained at $9 \% \mathrm{MK}$ and $10 \% \mathrm{MP}$.

Table: 3 28-Days Analysis of Cube

\begin{tabular}{|c|c|}
\hline $\begin{array}{l}\text { Replacement } \\
\text { percentage } \\
\text { MK-MP }(\%)\end{array} \quad$ of & $\begin{array}{l}\text { Compressive } \\
\text { Strength }\left(\mathrm{N} / \mathrm{mm}^{2}\right)\end{array}$ \\
\hline $0 \%-0 \%$ & 38.25 \\
\hline $3 \%-10 \%$ & 38.42 \\
\hline $6 \%-10 \%$ & 38.6 \\
\hline
\end{tabular}

\begin{tabular}{|c|c|}
\hline $9 \%-10 \%$ & 38.75 \\
\hline $12 \%-10 \%$ & 38.2 \\
\hline $15 \%-10 \%$ & 38.15 \\
\hline
\end{tabular}

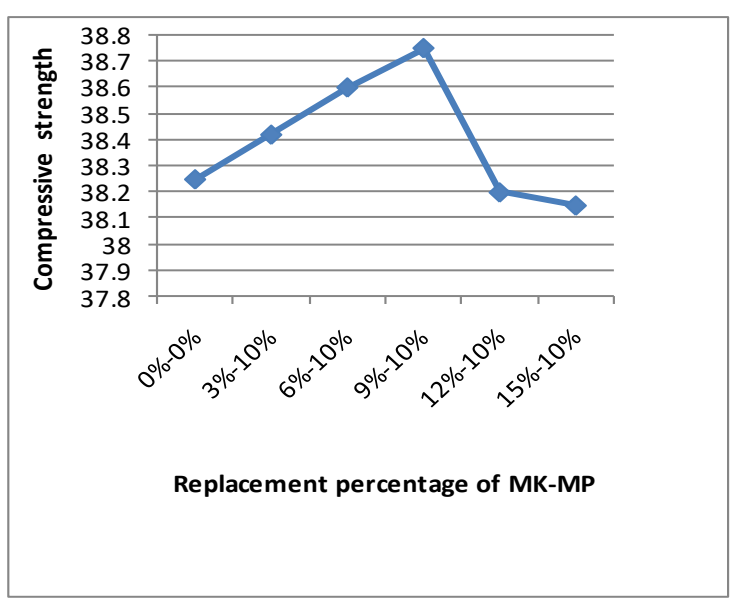

Graph 3:- 28-Days Analysis of Cube

\section{SPLIT TENSILE STRENGTH}

Split Tensile Strength likewise show the most extreme strength at MK9 blend. The Split Tensile strength for MK $3 \%$ expansion in $8.82 \%$, when contrasted with control specimen. The Split Tensile strength for MK 6\%, 9\% and $12 \%$ increments in $14.70 \%, 20.56 \%$ and $11.76 \%$ separately. MK 9\% increments in higher strength, when contrasted with all different blends. In any case, MK $18 \%$ reductions in $7.31 \%$ from MK $15 \%$.

Table 4:- 7-Days Split Tensile Strength of Concrete

\begin{tabular}{|c|c|}
\hline $\begin{array}{c}\text { Replacement of MK-MP } \\
(\%)\end{array}$ & $\begin{array}{c}\text { Split Tensile } \\
\text { Strength }\left(\mathbf{N} / \mathbf{m m}^{\mathbf{2}}\right)\end{array}$ \\
\hline $0 \%-0 \%$ & 2.14 \\
\hline $3 \%-10 \%$ & 2.27 \\
\hline $6 \%-10 \%$ & 2.39 \\
\hline $9 \%-10 \%$ & 2.52 \\
\hline $12 \%-10 \%$ & 2.51 \\
\hline $15 \%-10 \%$ & 2.49 \\
\hline
\end{tabular}

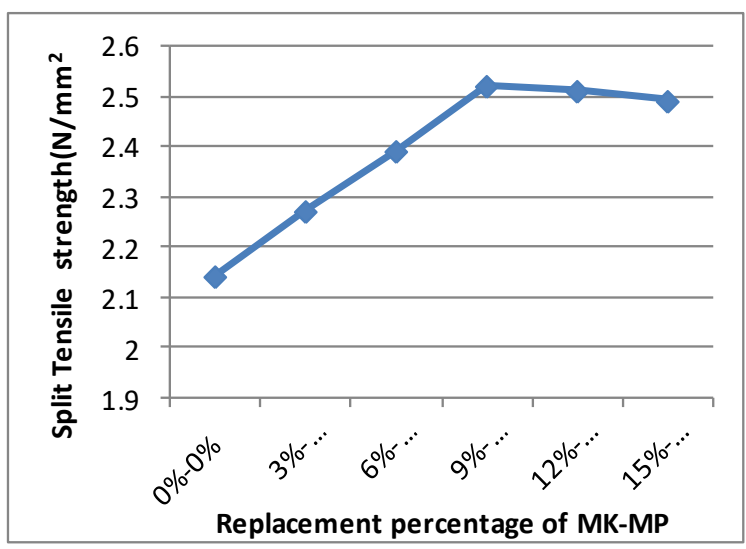

Graph 4:- 7-Days Split Tensile Strength of Concrete

Published By:

Blue Eyes Intelligence Engineering \& Sciences Publication 
Partial Replacement of Cement in Concrete by Metakaolin and Marble Dust

Table 5:- 14-Days Split Tensile Strength

\begin{tabular}{|c|c|}
\hline $\begin{array}{l}\text { Replacement of MK-MP } \\
(\%)\end{array}$ & $\begin{array}{lr}\text { Split } & \text { Tensile } \\
\text { Strength } & \left(\mathrm{N} / \mathrm{mm}^{2}\right)\end{array}$ \\
\hline $0 \%-0 \%$ & 2.44 \\
\hline $3 \%-10 \%$ & 2.51 \\
\hline $6 \%-10 \%$ & 2.76 \\
\hline $9 \%-10 \%$ & 3.07 \\
\hline $12 \%-10 \%$ & 3.03 \\
\hline $15 \%-10 \%$ & 3.01 \\
\hline
\end{tabular}

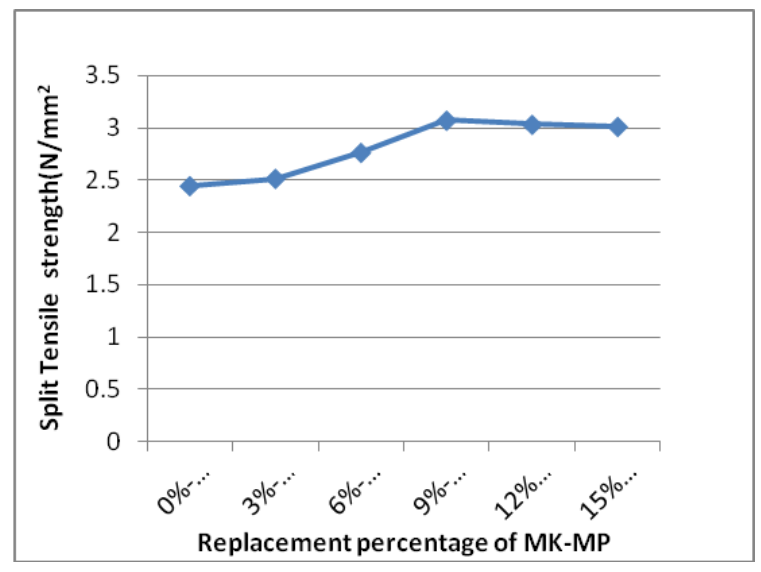

Graph 5:- 14-Days Split Tensile Strength

Table 6:- 28-Days Split Tensile Strength of Cylinder

\begin{tabular}{|c|c|}
\hline Replacement of MK-MP (\%) & $\begin{array}{l}\text { Split Tensile Strength } \\
\left(\mathbf{N} / \mathbf{m m}^{2}\right)\end{array}$ \\
\hline $0 \%-0 \%$ & 3.82 \\
\hline $3 \%-10 \%$ & 3.88 \\
\hline $6 \%-10 \%$ & 3.93 \\
\hline $9 \%-10 \%$ & 4.025 \\
\hline $12 \%-10 \%$ & 3.975 \\
\hline $15 \%-10 \%$ & 3.84 \\
\hline
\end{tabular}

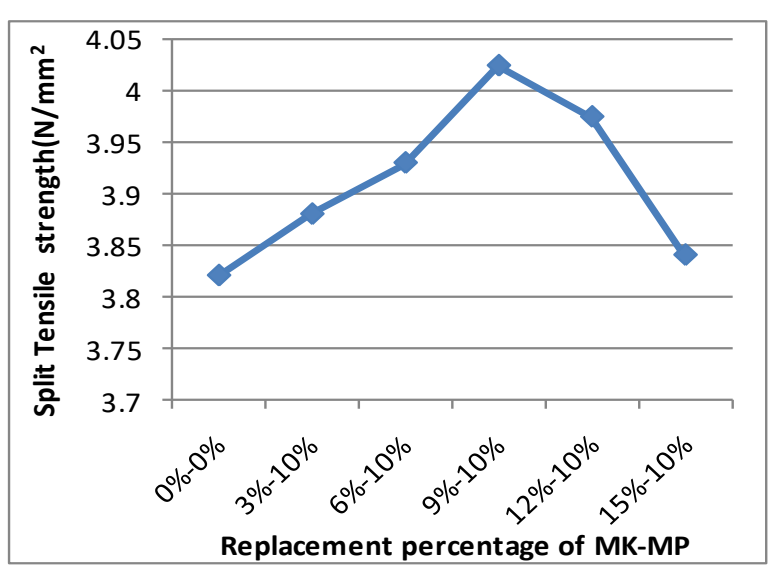

Graph 6:- 28-Days Split Tensile Strength of Cylinder

\section{Durability Analysis RCMT}

Solidness of cement is a significant factor for the toughness of solid structures. Presently Days, The properties of
Metakaolin as fantastic pozzolanic materials are explored by a few scientists. Quick Chloride Migration Test (RCMT) at 7 and 28 Days was performed on example for computation of chloride particle infiltration and kept at $60 \mathrm{~V}$ of current for 18hrs, what's more, microstructure of the concrete glues joining Metakaolin and MP was examined by EDAX tests. The rates of Metakaolin that supplant PC in this exploration are $0 \%, 3 \%, 6 \%, 9 \%, 12 \%$ and $15 \%$ by mass and MP as $0 \%$ (standard cement) and $10 \%$.

Table 7:- 7-Days Analysis of Rate of Penetration

\begin{tabular}{|c|c|}
\hline $\begin{array}{c}\text { Replacement of } \\
\text { MK-MP (\%) }\end{array}$ & $\begin{array}{c}\text { Rate of } \\
\text { penetration } \\
(\mathrm{m} / \mathrm{hr})\end{array}$ \\
\hline $0 \%-0 \%$ & 0.003370 \\
\hline $3 \%-10 \%$ & 0.003360 \\
\hline $6 \%-10 \%$ & 0.003351 \\
\hline $9 \%-10 \%$ & 0.002491 \\
\hline $12 \%-10 \%$ & 0.002498 \\
\hline $15 \%-10 \%$ & 0.002509 \\
\hline
\end{tabular}

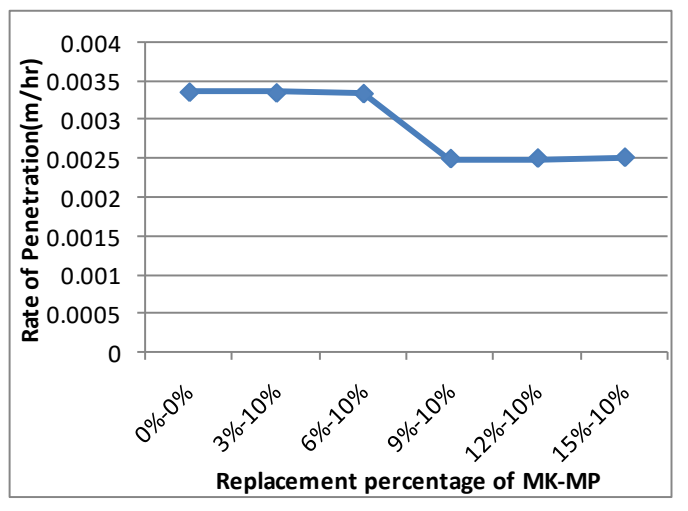

Graph 7:- 7-Days Analysis of Rate of Penetration

Table 8:- 28-Days Analysis of Rate of Penetration

\begin{tabular}{|c|c|}
\hline $\begin{array}{l}\text { Replacement of } \\
\text { MK-MD (\%) }\end{array}$ & $\begin{array}{c}\text { Rate of Penetration } \\
\text { (m/hr) }\end{array}$ \\
\hline $0 \%-0 \%$ & 0.00285 \\
\hline $3 \%-10 \%$ & 0.00235 \\
\hline $6 \%-10 \%$ & 0.002 \\
\hline $9 \%-10 \%$ & 0.00194 \\
\hline $12 \%-10 \%$ & 0.00206 \\
\hline $15 \%-10 \%$ & 0.00228 \\
\hline
\end{tabular}




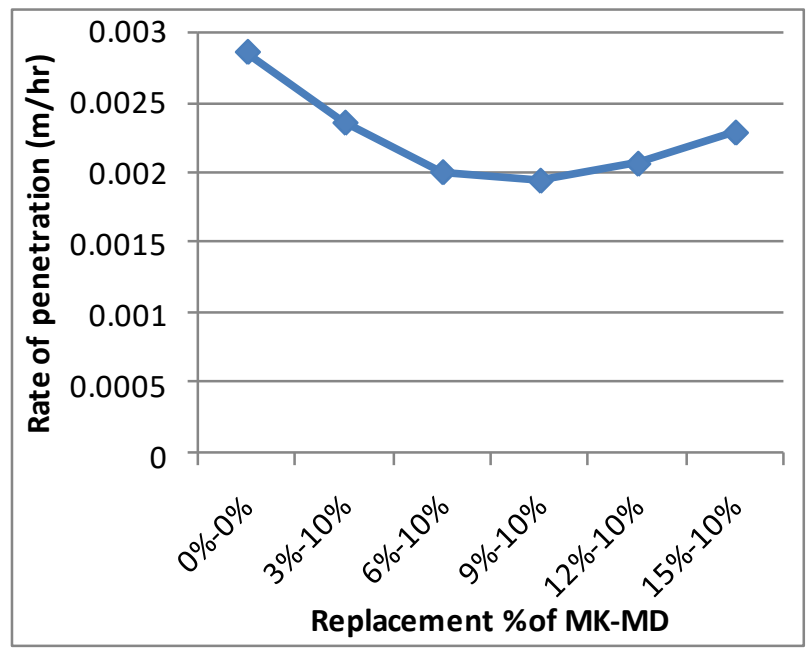

Graph 8:- 28-Days Analysis of Rate of Penetration

\section{COST ANALYSIS}

- Cost analysis of the concrete mixes is based on the cost of the materials only, and it has been analysed as per common Schedule of Rates (SoR) (as on April 2014).The mixes selected for calculation and analysis are those which could pass maximum properties of fresh mixed concrete.

- Cost savings and performance enhancement tend to be the driving forces behind the added value.. Engineers, Contractors, producers and owners are under greater pressure to produce better quality construction at lower costs of labour, materials and equipment.

- It is evident that urban areas produce large amount of waste product in the form of marble dust ,if used as admixture it will definitely reduce the cost.

- Similarly in india particularly in the state of jammu and Kashmir we have chine clay (Metakaolin), which is still a waste product as Govt. of the state does not utilize its potential, if this clay will be used as admixture, definetly in the state of jammu and Kashmir price of ordinary cement will come down as the raw material is available free of cost.

- Productivity improvements - The speed of construction, improves formed surface finish and thus reduces repair and patching costs, reduces maintenance costs and provides faster form and truck turn-around time.

- Reduced labour costs - The labour demands and compensates for lack of skilled workers to perform the rigorous work required for quality concrete construction

\section{CONCLUSIONS}

1. The supplanting of concrete with $9 \% \mathrm{MK}$ and $10 \% \mathrm{MP}$, give better outcomes better for qualities appeared in Fig 3 and Fig 6.

2. In the event that the level of MK is expanded above $9 \%$ keeping the level of MP as $10 \%$, there is decrease in quality of cement.

3.The penetrability test demonstrates that there is decline in porousness of cement with the expansion in measure of Metakaolin and Marble powder expansion.

4. The ideal rate for substitution of Concrete with Metakaolin and Marble powder was $9 \%$ and $10 \%$ individually for the two 3D squares and chambers. After $9 \% \mathrm{MK}$ and $10 \% \mathrm{MP}$, compressive quality just as split rigidity begins diminishing.

5 . There is decline in quality after $9 \%$ substitution of $\mathrm{MK}$ and $10 \%$ substitutions of MP yet toughness properties go on increment with increment in level of MK-MP.

6. Utilization of Metakaolin and Marble powder give GREEN CONCRETE.

7. Utilization of MK and MP spare our condition, since during the generation of MK and MP there is no emanation of carbon dioxide.

8. RCMT results demonstrates that solid made of Expansion of MK-MP has less rate of entrance of chloride particles. Subsequently Rate of entrance goes on decline with increment of level of MK-MP in concrete as appeared in fig 9. So we can say more strong cement is gotten.

\section{REFRENCES}

1. Concrete Technology-Oxford

2. www.engineeringcivil.com

3. http://www.ceratechinc.com/content/pdfs/patel-paper-final-5-10-12-2.pdf

4. www.applechemie.com

5. www.engr.psu.edu

6. FOSROC Constructive Solutions

7. Abdullah Anwar et.al (2014):Study of Compressive Strength of Concrete by Partial Replacement of Cement with Marble Dust Powder. Ird Indian ISSN (Print) : 2321-5747, Volume-2, Issue-3.

8. Sanjay N. Patil et.al(2014): Metakaolin- Pozzolanic Material ForCement in High Strength Concrete . (IOSR- JMCE) ISSN: 2278-1684, PP: 46-4.

\section{AUTHORS PROFILE}

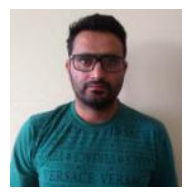

Shahid Ashraf Shah, Masters Of Technology Rimt University Bachelors Of Technology Ssm College Of Engineering And Technology

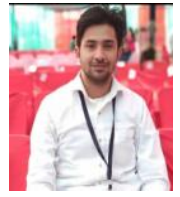

Ashish Kumar, Masters of technology Kurukshetra University Bachelors of technology Kurukshetra University Presently he is working as professor in Civil engineering Department of RIMT University Punjab India. 